\title{
Lava identification by paleomagnetism: a case study and some problems surrounding the 1631 eruption of Mount Vesuvius, Italy
}

\author{
Gennaro Conte-Fasano ${ }^{1 *}$, Jaime Urrutia-Fucugauchi ${ }^{1}$, Avto Goguitchaichvili ${ }^{1}$, Alberto Incoronato ${ }^{2}$, and Pasquale Tiano $^{2}$ \\ ${ }^{1}$ Laboratorio de Paleomagnetismo y Geofisica Nuclear, Instituto de Geofísica, UNAM, Ciudad Universitaria, 04510 Mexico, D.F., Mexico \\ ${ }^{2}$ Dipartimento di Scienze della Terra, Università degli Studi di Napoli Federico II, Largo S. Marcellino no. 10, 80138 Naples, Italy
}

(Received February 7, 2005; Revised February 23, 2006; Accepted March 7, 2006; Online published September 16, 2006)

\begin{abstract}
Detailed rock magnetic, paleomagnetic and absolute paleointensity studies of lava flows from the disputed 1631 Mount Vesuvius eruption are reported. The magnetic carrier consists of pseudo-single domain state Ti-poor titanomagnetites. Characteristic magnetization directions determined from detailed stepwise alternating field and thermal demagnetizations provide four new well-defined flow unit mean directions, with $\alpha_{95}$ ranging from $0.7^{\circ}$ to $2.6^{\circ}$. Paleodirections for 11 lava flows from 24-four flows studied previously appear to be related to the 1631 eruption, as indicated by their correlation to the early 17th century segment of the Italian paleosecular variation reference curve. This provides new evidence supporting the conclusion that the 1631 episode was an explosiveeffusive eruption. The paleointensity results obtained from this study are the first to be published for Mount Vesuvius, with virtual dipole moments of $9.24 \pm 1.8 \times 10^{22}$ and $13.5 \pm 0.4 \times 10^{22} \mathrm{Am}^{2}$ higher than the present-day geomagnetic field strength.
\end{abstract}

Key words: Paleosecular variation, Vesuvius volcano, 1631 eruption, paleointensity, Italy.

\section{Introduction}

The Somma-Vesuvius complex is localized in the Campania plain, a region of southern Italy bordered by Mesozoic carbonate platforms. Its formation was related to the tectonic activity that commence in the upper Pliocene, following formation of the Apennine belt. During the Quaternary, an intense and complex volcanic activity, in association with the subduction of the African plate beneath the Apennines chain, formed the large Roman-Campana Province (Di Girolamo, 1978). The main eruptive centers are localized in the Lazio (Vulsini, Vico, Sabatini) and Campania regions (Roccamonfina, Campi Flegrei, islands of Ischia and Procida, and Somma-Vesuvius).

The Somma-Vesuvius complex is one of the most dangerous volcanic complexes in southern Italy and is characterized mainly by explosive activity. Its eruptive history has been well documented in historical documents since 79 A.D. The Somma-Vesuvius complex is formed by two superposed volcanic structures: Vesuvius volcano, with a conical shape truncated at the summit, and the older Somma volcano, which represents the caldera of the volcanic complex. Stratigraphical observations and radiometric dating of some of the volcanic products intercalated between paleosoils have provided evidence of several cycles of eruptive activity, which begin usually with Plinian eruptions and have durations of less than 2000 years. The oldest prod-

\footnotetext{
*Also at: Instituto de Investigaciones Antropologicas, UNAM, Ciudad Universitaria, 04510 Mexico, D.F., Mexico.

Copyright (c) The Society of Geomagnetism and Earth, Planetary and Space Sciences (SGEPSS); The Seismological Society of Japan; The Volcanological Society of Japan; The Geodetic Society of Japan; The Japanese Society for Planetary Sciences; TERRAPUB.
}

ucts of the Somma volcano are estimated to date from about $25 \mathrm{ka}$ ago. In general, the activity of the Somma-Vesuvius complex can be divided into three long periods (Delibrias et al., 1979; Arnó et al., 1987; Santacroce, 1987). The first is the longest and oldest period of the volcanic complex, extending from $25 \mathrm{ka}$ ago to 79 A.D. (the large historic Plinian eruption); this period is characterized by the formation of the caldera. The second period includes the period of postcaldera activity, during which time there were several eruptions (at least 11), with the most famous being the 79 A.D. and 1631 'big' eruptions. The third period comprises the recent eruptive activity between 1631 and 1944 .

It is generally agreed that the 'big eruption' of Vesuvius in 1631 apparently occurred after 500 years of quiescence. The eruption started in early morning of 16 December 1631 with the formation of a tall Plinian column and culminated with the emission of pyroclastic flows and the generation of secondary lahars. This event is considered to be one of the most destructive episodes in the volcanic history of Mount Vesuvius and the last in which large pyroclastic flows were emitted. As far as the nature of this eruption is concerned, it was initially accepted that lava flows were associated to this eruption, as also supported by the first paleomagnetic study (Hoye, 1981) of two lava flows. The nature of this eruption was later questioned by Rosi and Santacroce (1984) and Rosi et al. (1993) who considered this event to be an explosive eruption, suggesting that lavas previously attributed to this event were much older and had probably been erupted during the 968-1039 period. Rolandi et al. (1991) and Rolandi and Russo $(1987,1989,1993)$ considered the 1631 event to be an explosive-effusive eruption, with the lavas already having been mapped by Le Hon (1865). To provide new data that would contribute towards solving this dispute, 


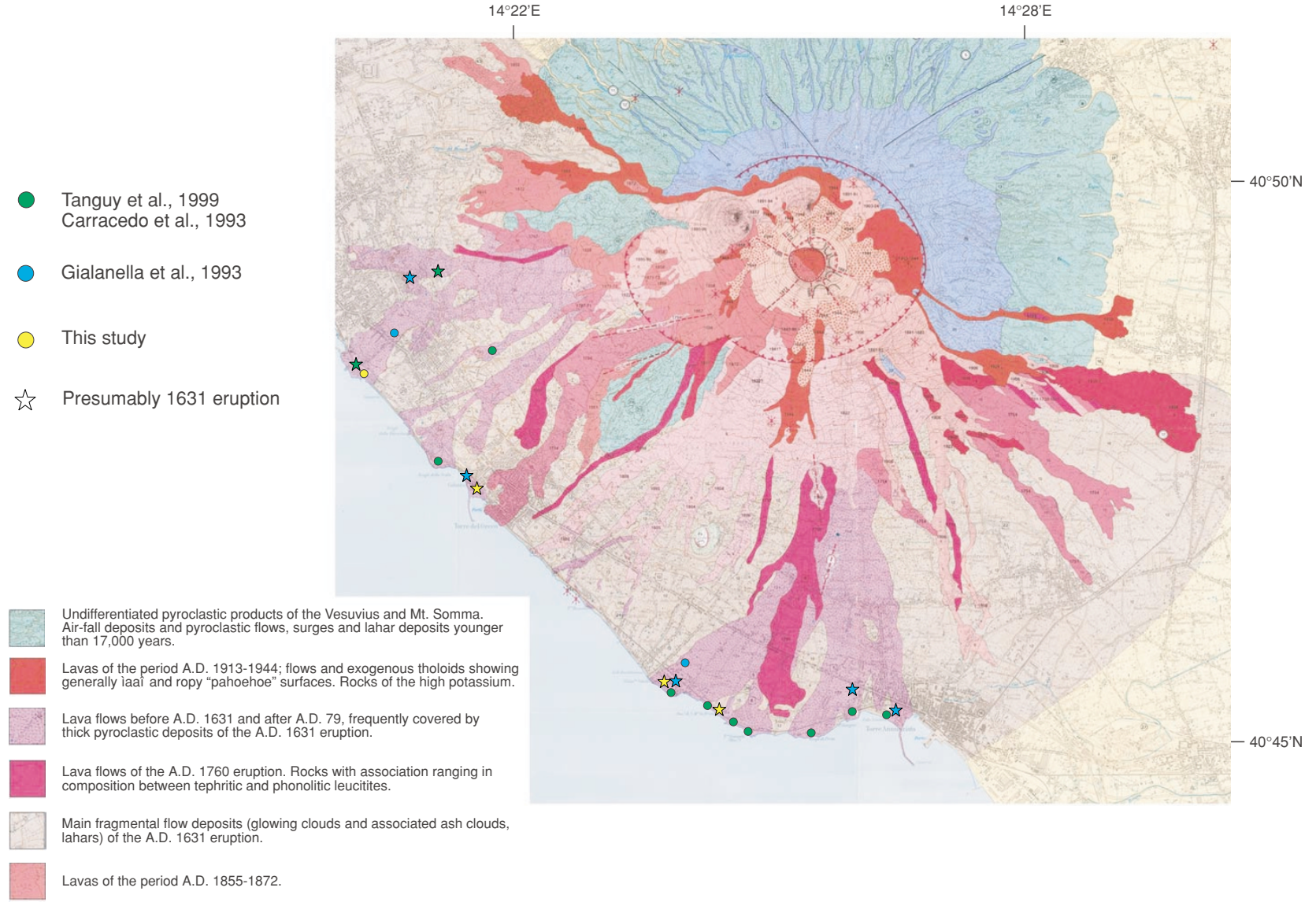

Fig. 1. Simplified geologic/volcanological map (modified from Principe et al., 1987) showing the location of paleomagnetic sampling sites (the location of sites studied by Tanguy et al. (1999) are not shown because these flows are reported in Carracedo et al. (1993) while those of Hoye (1981) are unknown). Stars refer to the presumed 1631 eruption.

new paleomagnetic studies were initiated in the early 1990s onwards, but these have provided conflicting results. For instance, Carracedo et al. (1993) did not recognize any flow associated to this eruption, a conclusion also reached by Tanguy et al. (1999), who re-sampled at the same sites the flows studied by Carracedo et al. (1993), and by Tanguy et al. (2003). In contrast, Gialanella et al. (1993) and Incoronato (1996) concluded that the 1631 eruption was characterized by an effusive phase. In particular, Incoronato (1996) showed that the disputed lava flows were characterized by mean directions of magnetization that clearly differed from those of the Medieval flows, the age of which had been paleomagnetically evaluated (968-1039) in a regional study (Incoronato and Del Negro, 2004).

The problem of the nature of the 1631 eruption is of actual relevance in the evaluation of potential volcanic hazards in the Vesuvius area. In this study, we re-examined previously published paleomagnetic data and assessed these data in combination with new, high-quality rock magnetic, paleomagnetic, and absolute paleointensity results that we obtained from lava flows that are presumed to be associated with the 1631 eruption. Nine to fifteen standard paleomagnetic cores were obtained from each site using a portable electric-powered drill that was oriented with a sun compass prior to removal. A total of 49 samples from four sites were collected (Fig. 1; modified from Principe et al., 1987). The cores were later sliced into standard specimen cores (diam- eter: $2.5 \mathrm{~cm}$; length: $2.1 \mathrm{~cm}$ ) for laboratory measurement. It cannot be ascertained that there are any sites obviously belonging to the same lava flow. In our sampling area, there was no evidence of previous samplings (i.e., with the field drilling technique).

\section{Rock Magnetic, Paleomagnetic and Paleointen- sity Measurements}

\subsection{Continuous susceptibility curves}

Three samples per lava flow were heated in air up to $600^{\circ} \mathrm{C}$ at a heating rate of $10^{\circ} \mathrm{C} / \mathrm{min}$ and then cooled at the same rate in order to identify magnetic minerals responsible for any remanent magnetization. Measurements were carried out using the Bartington susceptibility system MS2 equipped with a furnace. Curie temperatures were determined using the method of Prévot et al. (1983). Most samples yielded evidence of a single ferrimagnetic phase (Fig. 2(a), sample V47) with a Curie point compatible with those of Ti-poor titanomagnetites. The heating and cooling curves are reasonably reversible, which attests to the high thermal stability of samples. A few samples (Fig. 2(a), sample V48) yielded evidence of two ferrimagnetic phases during heating and cooling. The lower Curie points range between 220 and $300^{\circ} \mathrm{C}$, with the highest one being about $580^{\circ} \mathrm{C}$. Both Ti-rich and Ti-poor titanomagnetites seem to co-exist in these lava flows. 

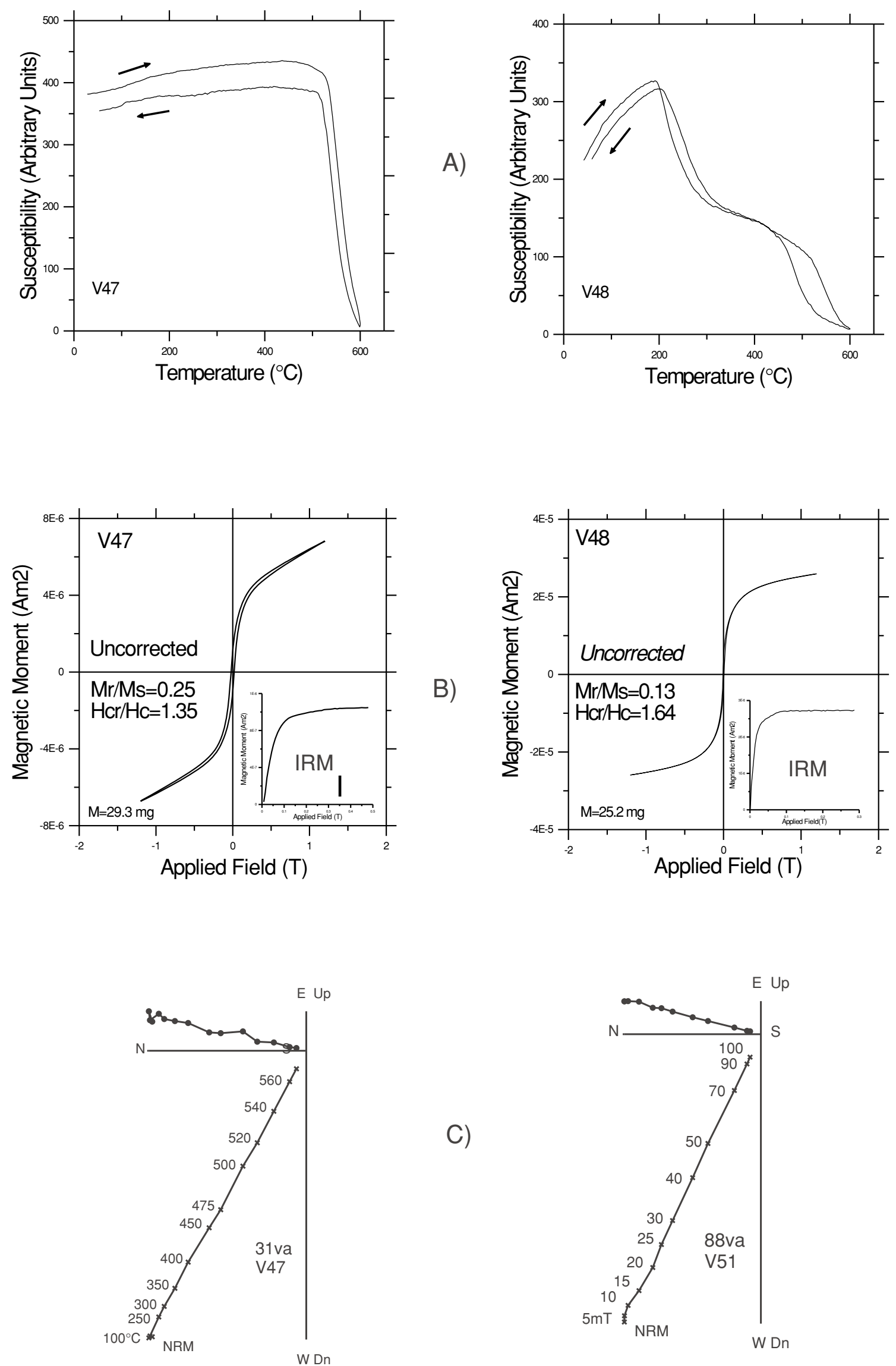

Fig. 2. (A) Susceptibility versus temperature (in air) curves of representative samples. The arrows indicate the heating and cooling curves. (B) Typical examples of hysteresis loops (uncorrected) and associated isothermal remanence acquisition curves of small chip samples from the studied volcanic flows. (C) Orthogonal vector plots of stepwise thermal or alternating field demagnetization of representative samples (stratigraphic coordinates). The numbers refer either to the temperatures in ${ }^{\circ} \mathrm{C}$ or to peak alternating fields in $\mathrm{mT}$. o. Projections into the horizontal plane; $\mathrm{x}$, projections into the vertical plane. 
Table 1. Mean paleodirections of cleaned remanence for Vesuvius lava flows that presumably erupted in 1631. N, Number of treated samples; n, number of specimens used for calculation; Dec, Declination; Inc, Inclination; $\mathrm{k}$ and $\alpha_{95}$, precision parameter and radius of $95 \%$ confidence cone of Fisher statistics, respectively. Note: in Tanguy et al. (1999) the sampling was performed on the same sites as those used by Carracedo et al. (1993), but the data are different.

\begin{tabular}{|c|c|c|c|c|c|c|}
\hline Site & Age & $\mathrm{n} / \mathrm{N}$ & $\operatorname{Dec}\left({ }^{\circ}\right)$ & $\operatorname{Inc}\left({ }^{\circ}\right)$ & $\alpha_{95}\left(^{\circ}\right)$ & $\mathrm{k}$ \\
\hline \multicolumn{7}{|c|}{ This Study } \\
\hline $\mathrm{V}-45$ & $1631 ?$ & $7 / 9$ & 7.4 & 66.7 & 2.4 & 611 \\
\hline $\mathrm{V}-47 *$ & $1631 ?$ & $9 / 13$ & 11.5 & 61.6 & 1.5 & 1124 \\
\hline V-48* & $1631 ?$ & $10 / 15$ & 13.8 & 65.1 & 2.6 & 340 \\
\hline $\mathrm{V}-51^{*}$ & $1631 ?$ & $11 / 12$ & 15.9 & 64.6 & 0.7 & 3863 \\
\hline \multicolumn{7}{|c|}{ Tanguy et al. (1999) } \\
\hline V8 & $1631 ?$ & 10 & 12.0 & 66.9 & 1.2 & 1454 \\
\hline V9 & $1631 ?$ & 15 & 20.1 & 59.4 & 1.2 & 943 \\
\hline V10 & $1631 ?$ & 9 & 16.8 & 60.4 & 1.4 & 1040 \\
\hline V11 & $1631 ?$ & 14 & 15.9 & 60.7 & 1.1 & 1198 \\
\hline V12 & $1631 ?$ & 10 & 19.0 & 60.4 & 1.8 & 634 \\
\hline \multicolumn{7}{|c|}{ Carracedo et al. (1993) } \\
\hline V8 & $1631 ?$ & 5 & 23.9 & 57.5 & 4.1 & 350 \\
\hline V9 & $1631 ?$ & 11 & 5.1 & 61.1 & 2.4 & 371 \\
\hline V10 & $1631 ?$ & 9 & 4.6 & 60.6 & 2.8 & 343 \\
\hline V11 & $1631 ?$ & 7 & 20.6 & 63.7 & 2.3 & 709 \\
\hline V12 & $1631 ?$ & 7 & 14.3 & 57.5 & 2.0 & 930 \\
\hline V14 & $1631 ?$ & 6 & 10.2 & 61.2 & 1.4 & 2376 \\
\hline V16* & $1631 ?$ & 9 & 11.8 & 65.3 & 2.7 & 358 \\
\hline V19 & $1631 ?$ & 5 & 11.3 & 60.3 & 2.1 & 1383 \\
\hline $\mathrm{V} 20^{*}$ & $1631 ?$ & 5 & 14.0 & 62.3 & 1.5 & 2477 \\
\hline V27 & $1631 ?$ & 4 & 6.4 & 66.1 & 2.4 & 1473 \\
\hline V31 & $1631 ?$ & 5 & 359.3 & 68.7 & 2.2 & 1171 \\
\hline \multicolumn{7}{|c|}{ Gialanella et al. (1993) } \\
\hline $1^{*}$ & $1631 ?$ & $5 / 9$ & 12 & 65 & 2.3 & 1100 \\
\hline $2^{*}$ & $1631 ?$ & $6 / 8$ & 14 & 64 & 1.6 & 1675 \\
\hline $8^{*}$ & $1631 ?$ & $6 / 7$ & 14 & 64 & 1.2 & 3120 \\
\hline 9 & $1631 ?$ & $4 / 12$ & 16 & 57 & 3.2 & 559 \\
\hline $10^{*}$ & $1631 ?$ & $6 / 7$ & 13 & 63 & 2.2 & 961 \\
\hline 11 & $1631 ?$ & $3 / 12$ & 4 & 66 & 4.8 & 666 \\
\hline $12 *$ & $1631 ?$ & $11 / 15$ & 14 & 63 & 1.9 & 585 \\
\hline \multicolumn{7}{|c|}{ Hoye (1981) } \\
\hline $\mathrm{A}^{*}$ & $1631 ?$ & $5 / 5$ & 14.2 & 63.4 & 1.5 & 2553 \\
\hline B & $1631 ?$ & $5 / 5$ & 15.6 & 66.2 & 3.1 & 627 \\
\hline
\end{tabular}

ALL* $\mathrm{N}=11, \mathrm{Dec}=13.5^{\circ}, \mathrm{Inc}=63.7^{\circ}, \alpha_{95}=0.7^{\circ}, \mathrm{k}=3738$

*Presumably 1631

\subsection{Hysteresis measurements}

All samples were subjected to magnetic hysteresis experiments using an AGFM "Micromag" apparatus in fields up to 1.4 Tesla. The hysteresis parameters (saturation remanent magnetization $M_{r}$, saturation magnetization $M_{s}$, and coercive force $H_{c}$ ) were calculated after correction for the paramagnetic contribution. The coercivity of remanence $\left(H_{c r}\right)$ was determined by applying a progressively increasing back-field after saturation. Typical hysteresis plots are shown in Fig. 2(b); as can be seen, the curves are quite symmetrical in all cases. Near the origin no potbellied and wasp-waisted behaviors were detected (Tauxe et al., 1996), which probably reflects the very restricted ranges of the opaque mineral coercivities. In the ratio plot of hysteresis parameters, samples fall in the pseudo-single-domain (PSD) grain size region (Day et al., 1977; Dunlop, 2002a, b). Isothermal remanent magnetization (IRM) acquisition curves indicate that saturation is reached in moderate fields of 100-200 mT, which points to some spinels as remanence carriers (most probably titanomagnetites).

\subsection{Paleodirections}

The intensity and direction of natural remanent magnetization (NRM) of 9-15 samples from each cooling unit were measured with both JR-5A and JR6 spinner magnetometers (sensitivity: approx. $10^{-9} \mathrm{Am}^{2}$ ). The coercivity and unblocking temperature spectra, stability, and vectorial composition of NRM were investigated by detailed progressive alternating field (AF) or stepwise thermal demagnetizations. AF demagnetization was carried out in eight to ten steps up to maximum fields of 70 or $100 \mathrm{mT}$ using a $\mathrm{Mol}$ spin AF demagnetizer, while thermal demagnetization was carried out in $12-14$ steps up $580^{\circ} \mathrm{C}$ using a non-inductive Schonstedt thermal demagnetizer.

In total, 39 specimens from four lava flows were demagnetized, with stable univectorial components being isolated in most cases (Fig. 2(c)). A small component, probably of 

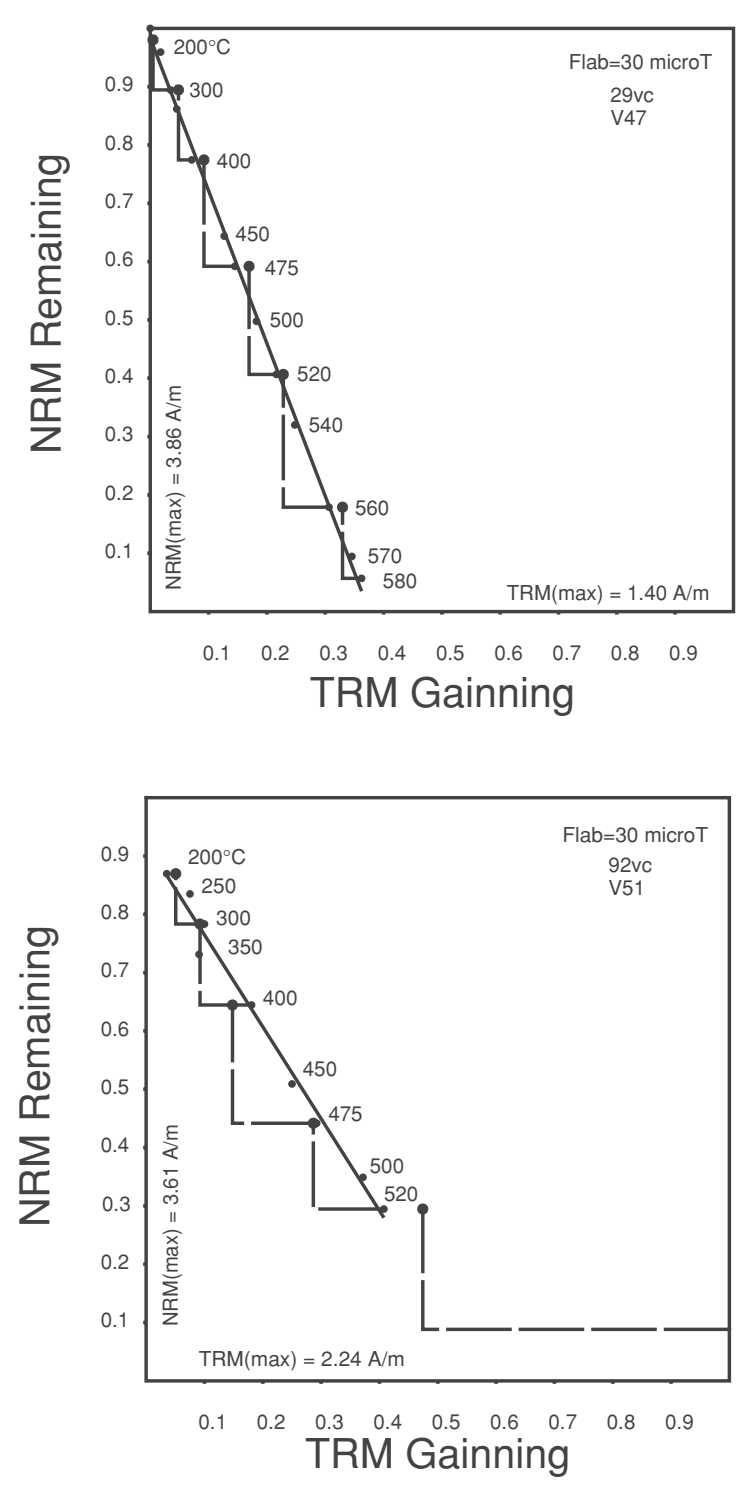
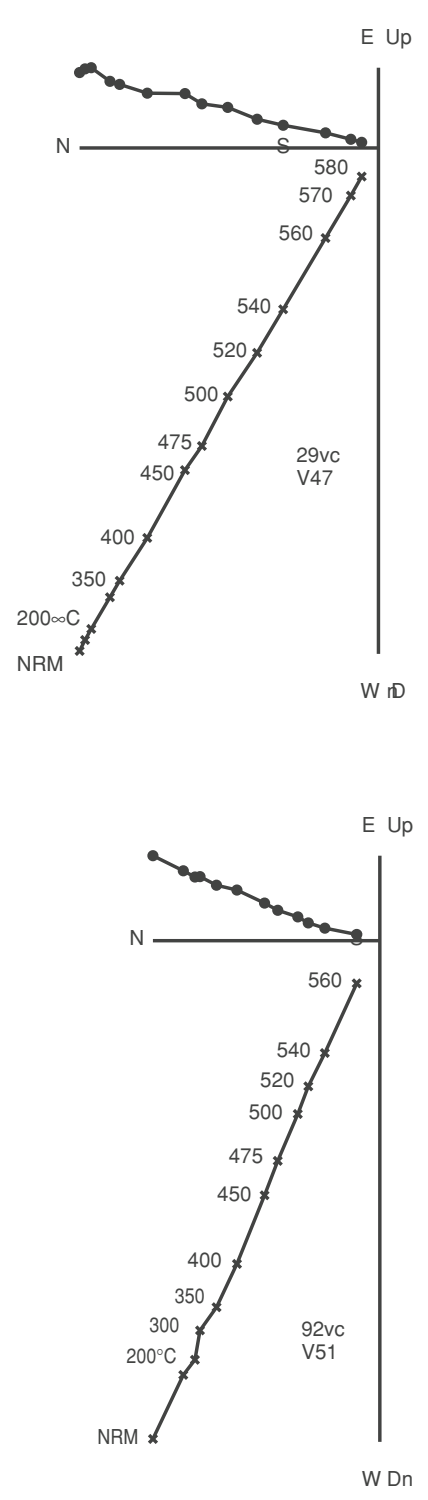

Fig. 3. The representative NRM-TRM plots and associated orthogonal diagrams from Vesuvius samples. The notations in the orthogonal diagrams are the same as in Fig. 2.

viscous origin, was easily removed during the first steps of demagnetization. The alternating field and thermal treatments, carried out on the same cores, generally yielded similar results. The greater part of the remanent magnetization was removed at temperatures between $520^{\circ}$ and $560^{\circ} \mathrm{C}$, which indicates low-Ti titanomagnetites as the main remanence carriers. The median destructive fields ranged between 30 and $40 \mathrm{mT}$, which is in agreement with data from the hysteresis experiments. Few samples showed more complex or unstable remanence behavior and no primary magnetization was determined; these samples were therefore rejected for further paleomagnetic analysis. The principal component analysis (PCA) of remanent magnetization for individual specimens was carried out using the linearity test of Kirschvink (1980) using 6-11 points for the mean direction determination. Site-mean directions were calculated by vector addition, which gives unit weight to sample directions. Site-mean directions and their statistical Fisherian parameters are summarized in Table 1 (Fisher, 1953).

\subsection{Thellier paleointensity experiments}

The method of Thellier (1959) as modified by Coe et al. (1978) was used to determine absolute paleointensities. For the experimental study, heating and cooling steps were carried out using a MDT80 furnace (Magnetic Measurement Ltd.) with the laboratory field set to 30 microTesla. Thirteen temperature steps were distributed between room temperature and $580^{\circ} \mathrm{C}$. Temperature reproducibility between two steps was in general better than $2^{\circ} \mathrm{C}$. During the experiment five control heating measurements (so-called "pTRM" checks) were performed after every second step to check the thermal alteration (Coe et al., 1978).

Thirty-four samples were pre-selected for the Thellier paleointensity experiment on the basis of stable, onecomponent magnetization accompanied with relatively high median destructive field (MDF) values, elevated blocking temperature, and reasonably reversible k-T curves. Some typical Arai-Nagata curves are shown in Fig. 3 (Nagata et al., 1963). We only accepted determinations that fulfilled 

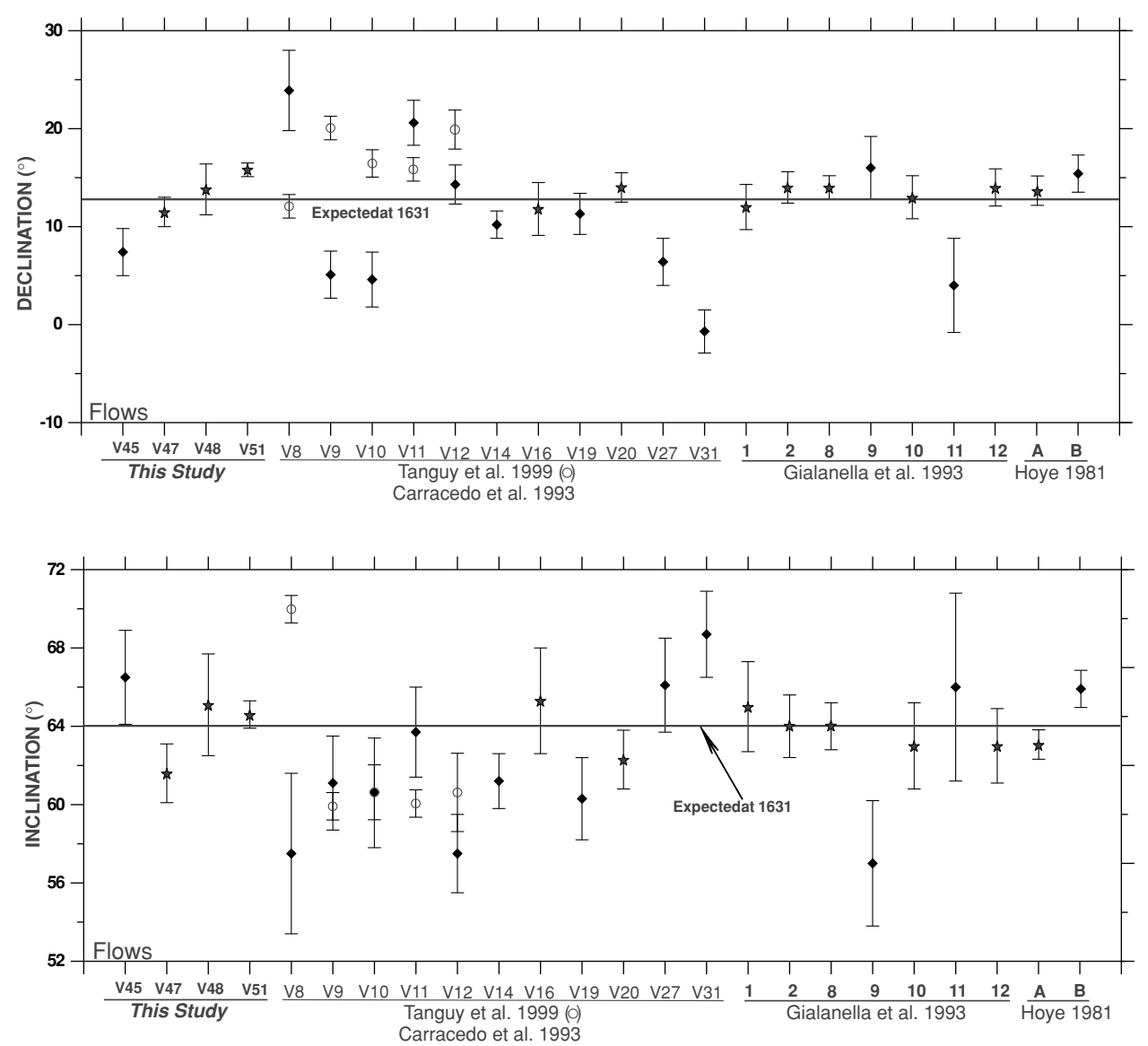

Fig. 4. Summary of characteristic unit mean paleodirections obtained from the Vesuvius ' 1631 ' lava flows. Stars refer to the presumed 1631 eruption.

the following criteria: (1) obtained from at least six NRMTRM (thermoreminant magnetization) points corresponding to a NRM fraction larger than one third, (2) yielded a quality factor (Coe et al., 1978) of about 5 or more; (3) with positive 'pTRM' checks - i.e., the deviation of the "pTRM" checks was less that $15 \%$ (Table 2).

\section{Main Results and Discussion}

Characteristic magnetization directions were successfully isolated for all samples, and flow unit directions were precisely determined (Table 1 ), with $\alpha_{95}$ ranging from $0.7^{\circ}$ to $2.4^{\circ}$. The thermomagnetic curves show that the remanence is carried by Ti-poor titanomagnetite resulting from oxy-exsolution of the original Ti-rich titanomagnetite during flow cooling; this most probably indicates the thermoremanent origin of a primary magnetization. The unblocking temperature spectra and relatively high coercivities point to PSD grains as being responsible for remanent magnetization.

With respect to the paleodirections, mean directions can be compared with a reference secular variation curve (SVC) for the area. The reference curve for the last few millennia in certain areas of Western Europe (France and Great Britain, for example) is reasonably well defined (Bucur, 1994; Gallet et al., 2002), in contrast those available for other areas, including Italy. There have also been considerable developments in the construction of secular variation curves and global databases (see Jackson et al., 2000; Le
Goff et al., 2002). Archeomagnetic data are still relatively scarce in Italy and, consequently, the reference curve relies on volcanic data and on relatively recent historical observatory observations (Evans and Hoye, 2005; Lanza et al., 2005). The integration of secular variation data derived from different materials and direct observations has also enabled evaluation of the precision and spatial validity (recalculation to near and far away sites) of directional results. The data from volcanic rocks on such directional results are usually characterized by high angular precision; nevertheless, sources of discrepancy and reduced accuracy have been observed at Italian volcanoes (e.g., Tanguy and Le Goff, 2004; Lanza et al., 2005) that are similar to results on other areas (e.g., Urrutia-Fucugauchi et al., 2004).

Two of reference secular variation curves currently being used for geomagnetic secular variation analyses and dating are available: the SISVC (Southern Italy Secular Variation Curve) (Incoronato et al., 2002; Incoronato and Del Negro, 2004) and the SIVC (South Italian Volcanic Curve) (Tanguy et al., 2003; largely derived from Tanguy et al., 1999). As these reference curves, derived using different procedures, have been extensively discussed in Incoronato et al. (2002) (see also Incoronato and Del Negro, 2004 and Conte et al., 2006), we will briefly summarize only some of the main arguments here.

The SISVC relies on:

1) Analysis of the entire coercivity/blocking temperature spectra by subjecting each specimen to complete de- 


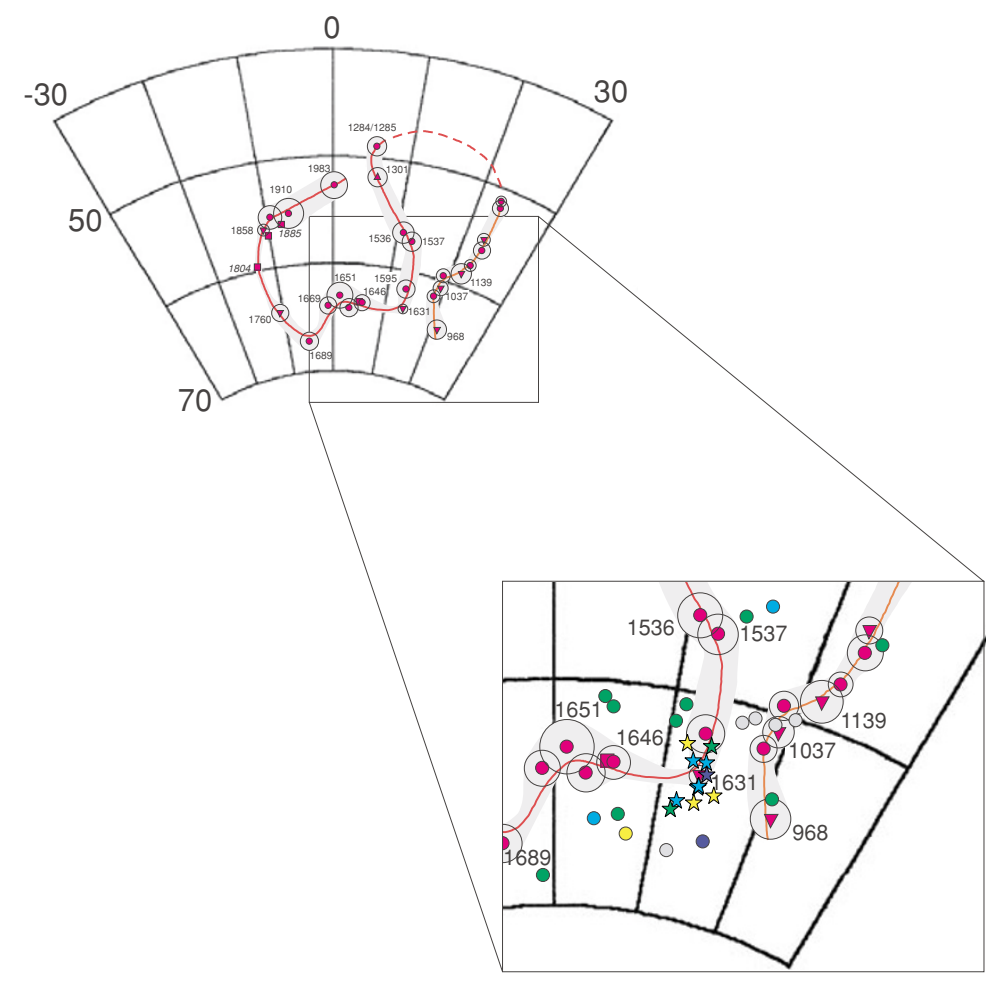

This Study 0

Tanguy et al. 19990

Carracedo et al. 1993 •

Gialanella et al. 1993 •

Hoye 1981 •

Presumably 1631 eruption $\lesssim$

Fig. 5. Site-mean characteristic paleodirections from Vesuvius lava flows presumably related to the 1631 eruption with reference to the Southern Italy secular variation curve (Incoronato et al., 2002). The statistical uncertainties were used to draw the swath of error. Squares refer to historical measurements of the geomagnetic field in Rome and the stars refer to the presumed 1631 eruption.

magnetization in order to check the presence of magnetization components.

2) Information on the magnetic carriers.

3) Separation of the different magnetization components achieved by PCA. In dealing with lava flows emplaced a few hundred years ago only, very low maximum angular deviation have been used in order to separate primary components of magnetization from secondary ones that have been acquired in such a small time interval of a few hundred years only, although this caused many specimens or sites to be rejected.

4) Relocation of geomagnetic/magnetization directions, via the inclined geocentric dipole, performed within a few hundred kilometers only.

The bulk of the data on which the SIVC relies derives from measurements of partial progressive alternating magnetic field demagnetization (PAFD); there are no PCA analysis, Zijderveld diagrams, and information on magnetic carriers available.

We will take the different procedures leading to these SVCs when using the SISVC in our discussion of the results. To draw the swath of error on the curve we used the statistical uncertainties.

Mean directions from 11 flows fall close to the early 17 th century segment. The difference found between the paleodirections retrieved from the reference curve and those from the pyroclastic lava (unambiguously pertaining to this eruption) seems to be related to the mechanism of remanence acquisition in the pyroclastic flow. The evidence of the unsuitability of pyroclastic lava as a basis for determin- ing a reference direction comes directly from Carracedo et al.'s (1993) paper. The main problem is that the temperature of emplacement of the 1631 pyroclastic flow is unknown. These rocks most likely carry a partial thermoremanence instead of a full thermoremanent magnetization. Moreover, rather unstable magnetic behavior was detected during the thermal stepwise demagnetization due to the some lithic (clasts) inclusion in the juvenile pumice. Strictly speaking, only lava flow V48 from the present study matches the corresponding segment of the reference curve (Figs. 4 and 5), although two other lavas, V47 and V51, also show similar paleodirections close to this reference curve. However, the absolute paleointensities of the latter differ (Table 2). Site V45 has paleodirections that differ considerably from the reference curve. The lava flows from the Carracedo et al. (1993) study yield highly scattered directional results. Two sites (V16 and V20) may be also related to the 1631 eruption, while all flows (excepting two sites 9 and 11) studied by Gialanella et al. (1993) give directions concordant with the reference curve, as far as is reported in his work. The same applies for site A of Hoye (1981).

The use (and usefulness) of the reference curves also presents problems, including correct age correlation, when distinct curve segments are relatively close-which is the case for the 10-12th century and 16-17th century segments of the Italian data. However, the general angular distribution and tendency of the 11 sites presumably related to the 1631 eruption correspond to the 16-17th century segment of the Italian data set (Fig. 5). With respect to the other sites, it seems that only few of them may be directly attributed to the medieval ages (sites V8 and V11 of Carracedo et al., 
Table 2. First paleointensity results from the Vesuvius. N, The number of NRM-TRM points used for paleointensity determination; $T_{\min }-T_{\max }$, the temperature interval used; $f, g$, and $q$, the fraction of extrapolated NRM used, the gap factor and quality factor (Coe et al., 1978), respectively. Fe is the individual paleointensity estimate with associated error, VDM and VDMm are individual and average virtual dipole moments.

\begin{tabular}{|c|c|c|c|c|c|c|c|c|c|}
\hline Site & Sample & $\mathrm{N}$ & $\begin{array}{c}T_{\min }-T_{\max } \\
{ }^{\circ} \mathrm{C}\end{array}$ & $f$ & $g$ & $q$ & $\begin{array}{c}F_{E} \pm \sigma\left(F_{E}\right) \\
(\mu \mathrm{T})\end{array}$ & $\begin{array}{c}\text { VDM } \\
10^{22} \mathrm{Am}^{2}\end{array}$ & $\begin{array}{c}\text { VDMm } \\
10^{22} \mathrm{Am}^{2}\end{array}$ \\
\hline \multirow[t]{6}{*}{ V47 } & V29 & 14 & $20-580$ & 0.96 & 0.90 & 69.24 & $79.5 \pm 0.9$ & 13.7 & $13.5 \pm 0.4$ \\
\hline & V31 & 14 & $20-580$ & 0.96 & 0.90 & 46.69 & $83.2 \pm 1.5$ & 14.0 & \\
\hline & V32 & 14 & $20-580$ & 0.95 & 0.90 & 97.08 & $77.6 \pm 0.7$ & 13.3 & \\
\hline & V33 & 14 & $20-580$ & 0.96 & 0.89 & 60.40 & $73.9 \pm 1.1$ & 12.9 & \\
\hline & V34 & 14 & $20-580$ & 0.93 & 0.90 & 82.86 & $79.5 \pm 0.8$ & 13.7 & \\
\hline & V35 & 14 & $20-580$ & 0.94 & 0.90 & 79.39 & $79.6 \pm 0.8$ & 13.5 & \\
\hline \multirow[t]{5}{*}{ V51 } & V88 & 5 & $350-500$ & 0.51 & 0.74 & 4.09 & $51.3 \pm 4.7$ & 8.34 & $9.24 \pm 1.8$ \\
\hline & V90 & 5 & $350-500$ & 0.47 & 0.74 & 3.83 & $53.4 \pm 4.9$ & 8.48 & \\
\hline & V91 & 6 & $350-520$ & 0.53 & 0.78 & 5.13 & $57.8 \pm 4.7$ & 9.24 & \\
\hline & V92 & 9 & $200-520$ & 0.63 & 0.85 & 12.31 & $76.4 \pm 3.3$ & 12.3 & \\
\hline & V95 & 6 & $350-520$ & 0.56 & 0.77 & 6.65 & $48.8 \pm 3.2$ & 7.89 & \\
\hline
\end{tabular}

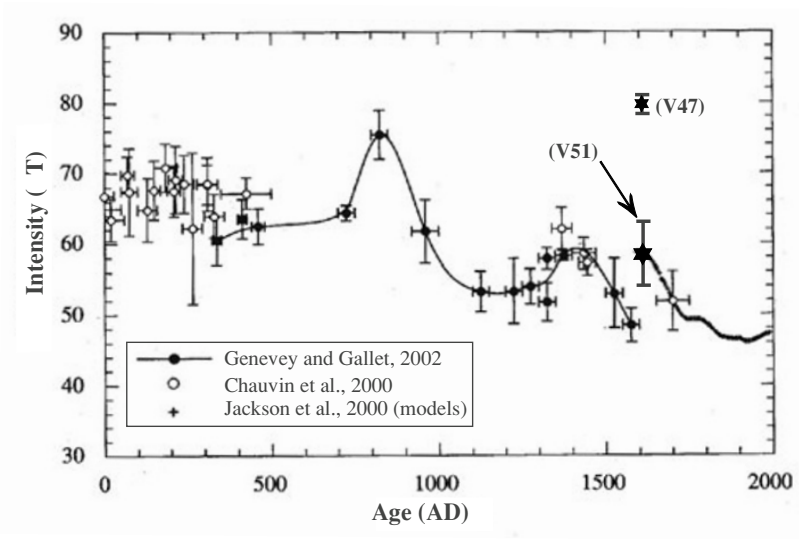

Fig. 6. Evolution of the geomagnetic field intensity in Western Europe during the last two millennia as assessed from archeomagnetic data (Chauvin et al., 2000; Genevey and Gallet, 2002) and geomagnetic field models (Jackson et al., 2000). All data are reduced to the latitude of Paris, France.

1993 and sites V9, V10, V11, V12 of Tanguy et al., 1999).

In summary, the paleodirections of 11 of the lava flows from the 24 flows studied coincide within associated uncertainties with the corresponding segment of the SISVC. Thus, this major event in Vesuvius volcanic history-the 1631 eruption-can be considered to be an explosiveeffusive eruption.

Eleven samples yielded acceptable paleointensity estimates; these estimates are the first published to date for Mount Vesuvius (Table 2). The fraction of the NRM $f$ used for paleointensity determination ranges between 0.47 and 0.96 , and the quality factor $q$ from 3.8 to 97.1 (generally being greater than 5). NRM end points obtained from the Thellier experiments at each step are reasonably linear and point to the origin (Fig. 3); no deviation of the NRM left direction towards the applied laboratory field was observed, indicating the high technical quality of the paleointensity determinations. Obtained VDMs (virtual dipole moments) $-9.24 \pm 1.8 \times 10^{22} \mathrm{Am}^{2}$ for site V51 and $13.5 \pm 0.4 \times 10^{22} \mathrm{Am}^{2}$ for site V47-are higher than the present-day geomagnetic field strength.

Absolute paleointensity studies on recent Italian lava flows are mainly devoted to the Etna volcano. However, the geomagnetic significance of the data has recently been seriously questioned by Calvo et al. (2002) and, consequently, these data cannot be used as reference material. However, an abundance of good archeointensity data has been recently reported for Western Europe (mainly from France). Chauvin et al. (2000) and Genevey and Gallet (2002) compiled archeointensity results for the last two millennia. In addition, these authors obtained numerous intensity determinations on well-dated potteries, which has greatly improved the archeointensity reference curve for Western Europe (Fig. 6). The data derived from the Jackson et al. (2000) model are also incorporated in this curve. Two paleointensity determinations obtained from Mount Vesuvius lava flows (V47 and V51, see also Table 2) are reduced to the latitude of Paris (Fig. 6) as well as all data from Chauvin et al. (2000) and Genevey and Gallet (2002). There is a good agreement with the value obtained from flow V51 and the historical geomagnetic field model (Jackson et al., 2000) at about 1631 (Fig. 6). It is probable that this lava also belongs to the 1631 eruption even though it shows slightly different magnetic declination with respect to the SISVC (Fig. 4). In contrast, the intensity retrieved from lava flow V47 differs significantly from the curve, showing an unusually high geomagnetic field strength that better matches with segment on the 8 th to 10 th centuries. It may be speculated that this lava erupted during the 968-1039 period. Alternatively, this unusually high absolute intensity value may be due to the problems related to the Thellier paleointensity determination.

\section{Conclusion}

The paleodirections of 11 lava flows out of 24 (this study; Hoye, 1981; Carracedo et al., 1993; Gialanella et al., 1993; Tanguy et al., 1999) coincide-within associated uncertainties - with the corresponding segment of the Southern Italy Secular Variation Curve. Thus, we conclude that this major event in Vesuvius volcanic history represented an explosive-effusive eruption.

Acknowledgments. We acknowledge the comments by Dr. Laurie Brown of the journal review board. AG acknowledges the financial support of a Conacyt grant 42661. 


\section{References}

Arnó, V., C. Principe, M. Rosi, R. Santacroce, A. Sbrana, and M. F. Sheridan, Eruptive history, in "Somma-Vesuvius" Quaderni de "La Ricerca Scientifica” C.N.R., edited by R. Santacroce, 114, 243 pp., 1987.

Bucur, I., The direction of the terrestrial magnetic field in France, during the last 21 centuries. Recent progress, Earth Planet. Sci. Lett., 87, 95109, 1994.

Calvo, M., M. Prévot, M. Perrin, and J. Riisager, Investigating the reasons for the failure of paleointensity experiments: A study on historical lava flows from Mt. Etna (Italy), Geophys. J. Int., 149, 44-63, 2002.

Carracedo, J., C. Principe, M. Rosi, and V. Soler, Time correlation by palaeomagnetism of the 1631 eruption of Mount Vesuvius. Volcanological and volcanic hazard implications, J. Volcanol. Geothermal Res., 58, 203-209, 1993.

Chauvin, A., Y. Garcia, P. Lanos, and F. Laubenheimer, Paleointensity of the geomagnetic field recovered on archeomagnetic sites from France, Phys. Earth Planet. Int., 120, 111-136, 2000.

Coe, R., S. Gromme, and E. A. Mankinen, Geomagnetic paleointensity from radiocarbon-dated lava flows on Hawaii and the question of the Pacific non-dipole Low, J. Geophys. Res., 83, 1740-1756, 1978.

Conte, G., J. Urrutia-Fucugauchi, A. Goguitchaichvili, and A. Incoronato, Paleomagnetic dating of lava flows of uncertain age, Somma-Vesuvius volcanic complex (Southern Italy), Int. Geol. Rev., 48(4), 349-359, 2006.

Day, R., M. Fuller, and V. A. Schmidt, Hysteresis properties of titanomagnetites: Grain size and compositional dependence, Phys. Earth Planet. Int., 13, 260-267, 1977.

Delibrias, G., G. Di Paola, M. Rosi, and R. Santacroce, La storia eruttiva del complesso vulcanico Somma-Vesuvio ricostruita nelle successioni piroclastiche del M. te Somma, Rend. Soc. It. Mineral. Petrol., 35, 411438, 1979.

Di Girolamo, P., Geotectonic setting of Miocene-Quaternary volcanism in and around the Eastern Tyrrhenian sea border (Italy) as deduced from major element geochemistry, Bull. Volcanol., 41, 229-250, 1978.

Dunlop, D. J., Theory and application of the Day plot (Mrs/Ms versus $\mathrm{Hcr} / \mathrm{Hc})$ 1: Theoretical curves and tests using titanomagnetite data, $J$. Geophys. Res., 107(B3), 10.1029/2001JB000486, 2002a.

Dunlop, D. J., Theory and application of the Day plot (Mrs/Ms versus $\mathrm{Hcr} / \mathrm{Hc}$ ) 2: Application to data for rocks, sediments, and soil, J. Geophys. Res., 107(B3), 10.1029/2001JB000487, 2002b.

Evans, M. E. and G. S. Hoye, Archaeomagnetic results from southern Italy and their bearing on geomagnetic secular variation, Phys. Earth Planet. Int., 151, 155-162, 2005.

Fisher, R. A., Dispersion on the sphere, Proc. R. Soc. London Ser. A, 217, 295-305, 1953.

Gallet, Y., A. Genevey, and M. Le Goff, Three millennia of directional variation of the earths magnetic field in western Europe as revealed by archeological artifacts, Phys. Earth Planet. Int., 131, 81-89, 2002.

Genevey, A. and Y. Gallet, Intensity of the geomagnetic field in western Europe over the past 2000 years: New data from ancient French poteries, J. Geophys. Res., 107(B11), 2285, 10.1029/2001JB000701, 2002.

Gialanella, R., A. Incoronato, F. Russo, and G. Nigro, Magnetic stratigraphy of Vesuvius products. I-1631 lavas, J. Volcanol. Geothermal Res., 58, 211-215, 1993

Hoye, G. S., Archaeomagnetic secular variation record of Mount Vesuvius. Nature, 291, 216-218, 1981.

Incoronato, A., Magnetic stratigraphy procedures in volcanic areas: the experience at Vesuvius. Palaeomagnetic and Tectonics of the Mediterranean Region. Geological Soc. Special Pub., 105, 367-371, 1996.

Incoronato, A. and C. Del Negro, Magnetic Stratigraphy Procedures at Etna, in The Mt. Etna Volcano, edited by A. Bonaccorso, S. Calvari, M. Coltelli, C. Del Negro, and S. Falsaperla, AGU Geophys Monogr. Ser., 143, 263-271, 2004.

Incoronato, A., A. Angelino, R. Romano, A. Ferrante, R. Sauna, G. Vanacore, and C. Vecchione, Retrieving geomagnetic secular variations from lava flows: evidence from Mount Arso, Etna and Vesuvius (southern Italy), Geophys. J. Int., 149, 724-730, 2002.

Jackson, A., A. Jonkers, and M. Walker, Four centuries of geomagnetic secular variation from historical records, Philos. Trans. R. Soc. London, Ser. A, 358, 957-990, 2000.
Kirschvink, J. L., The least-squares line and plane and the analysis of palaeomagnetic data, Geophys. J. R. Astr. Soc., 62, 699-718, 1980.

Lanza, R., A. Meloni, and E. Tema, Historical measurements of the Earth's magnetic field compared with remanence directions from lava flows in Italy over the last four centuries, Phys. Earth Planet. Int., 148, 97-107, 2005.

Le Hon, H., Histoire complete de la grande eruption du Vesuve de 1631 (With a topographic map of Vesuvius lavas from 1631 till 1861), Bull. R. Acad. Sci. Lett. Beaux Arts, Belg., 20, 483-538, 1865.

Le Goff, M., Y. Gallet, A. Genevey, and N. Warmé, On archeomagnetic secular variation curves and archeomagnetic dating, Physics of the Earth and Planetary Interiors, 134, 203-211, 2002.

Nagata, T., R. A. Fisher, and K. Momose, Secular variation of the geomagnetic total force during the last 5000 years, J. Geophys. Res., 68 , 5277-5281, 1963.

Prévot, M., R. S. Mankinen, S. Gromme, and A. Leccaille, High paleointensity of the geomagnetic field from thermomagnetic studies on rift valley pillow basalts from the middle Atlantic ridge, J. Geophys. Res., 88, 2316-2326, 1983.

Principe, C., M. Rosi, R. Santacroce, and A. Sbrana, Explanatory Notes to the Geological Map of Vesuvius. Quaderni de "La Ricerca Scientifica", CNR, Roma, 114, 8, 11-51, 1987.

Rolandi, G. and F. Russo, Contributo alla conoscenza dell'attività storica del Vesuvio. La stratigrafia di Villa Inglese (Torre del Greco), Rend. Acad. Sci. Fis. Mat. Napoli, 54, 123-127, 1987.

Rolandi, G. and F. Russo, Contributo alla conoscenza dell'attività storica del Vesuvio: dati stratigrafici e vulcanologici nel settore meridionale tra Torre del Greco, località Villa Inglese, e Torre Annunziata, Boll. Soc. Geol. Ital., 108, 521-536, 1989.

Rolandi, G. and F. Russo, L'eruzione del Vesuvio del 1631, Boll. Soc. Geol. Ital., 112, 315-332, 1993.

Rolandi, G., A. Barrella, A. Borrelli, and G. D’Alessio, The 1631 Vesuvian eruption, Int. Conf. on Active Volcanoes and Risk Mitigation. Abstr., 91, 1991.

Rosi, M. and R. Santacroce, The famous AD 1631 eruption of Vesuvius: a revised interpretation in light of historical and volcanological data, Workshop on Volcanic Blast, Mount St. Helens, abstr., 1984.

Rosi, M., C. Principe, and R. Vecchi, The 1631 eruption of Vesuvius reconstructed from the review of chronicles and study of deposits, $J$. Volcanol. Geotherm. Res., 58, 151-182, 1993.

Santacroce, R., Somma-Vesuvius. Quaderni de "La Ricerca Scientifica", CNR, Roma 114, 8, 243 pp., 1987.

Tanguy, J. C. and M. Le Goff, Distortion of the geomagnetic field in volcanic terrains: an experimental study of the Mount Etna stratovolcano, Phys. Earth Planet. Int., 141, 59-70, 2004.

Tanguy, J. C., M. Le Goff, V. Chillemi, A. Paiotti, C. Principe, S. La Delfa, and G. Patanè, Variation séculaire de la direction du champ géomagnétique enregistrée par les laves de l'Etna et du Vésuve pendant les deux derniers millénaires, C. R. Acad. Sc. Paris Sci. Terre Planèt., 329, 557-564, 1999.

Tanguy, J. C., M. Le Goff, V. Chillemi, A. Paiotti, C. Principe, S. La Delfa, and G. Patanè, Archeomagnetic dating of Mediterranean volcanics of the last 2100 years: validity and limits, Earth Planet. Sci. Lett., 211, 111-124, 2003.

Tauxe, L., T. A. T. Mullender, and T. Pick, Pot-bellies, wasp-waists and superparamagnetism in magnetic hysteresis, J. Geophys. Res., 95, 1233712350, 1996.

Thellier, E. and O. Thellier, Sur l'intensite de champ magnetique terrestre dans le passe historique et geologique, Ann. Geophys., 15, 285-376, 1959.

Urrutia-Fucugauchi, J., L. Alva-Valdivia, A. Goguitchaichvili, M. L. Rivas, and J. Morales, Palaeomagnetic, rock-magnetic and microscopy studies of historic lava flows from Paricutin volcano, Mexico: Implications for the deflection of palaeomagnetic measurements, Geophys. J. Int., 156, 431-442, 2004.

G. Conte-Fasano (e-mail: gennaro@geofisica.unam.mx), J. UrrutiaFucugauchi, A. Goguitchaichvili, A. Incoronato, and P. Tiano 